\title{
An adaptation strategy to urban heat: hospital rooms with radiant cooling accelerate patient recovery
}

\author{
Christina Hoffmann $\mathbb{1}^{1}$, Uta Liebers ${ }^{1}$, Philipp Humbsch ${ }^{1}$, Marija Drozdek ${ }^{1}$, Georg Bölke $\mathbb{C}^{1}$, \\ Peter Hoffmann $\mathbb{D}^{1}$, Adrien Holzgreve ${ }^{1,2}$, Gavin C. Donaldson ${ }^{3}$ and Christian Witt $^{1}$
}

${ }^{1}$ Dept of Outpatient Pneumology, Charité - Universitätsmedizin Berlin, Corporate Member of Freie Universität Berlin and HumboldtUniversität zu Berlin, Berlin, Germany. ${ }^{2}$ Dept of Nuclear Medicine, University Hospital, Munich, Germany. ${ }^{3}$ Airways Disease Section, National Heart and Lung Institute, Imperial College London, London, UK.

Corresponding author: Christian Witt (christian.witt@charite.de)

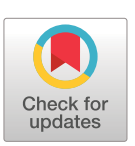

This article has been revised according to the correction published in ERJ Open Res 2021; 7 : 50881-2020 [https://10.1183/23120541.508812020]

Copyright @The authors 2021

This version is distributed under the terms of the Creative Commons Attribution NonCommercial Licence 4.0. For commercial reproduction rights and permissions contact permissions@ersnet.org

This article has supplementary material available from openres.ersjournals.com

Received: 24 Nov 2020 Accepted: 27 May 2021

First published: 31 Aug 2021

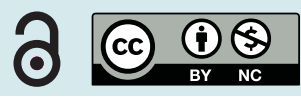

Shareable abstract (@ERSpublications)

A radiant cooling system in hospital patient rooms provides clinical benefits for patients with respiratory disease exacerbations during summertime. Patients hospitalised in rooms with air convection free radiant cooling are discharged earlier. https://bit.ly/3p9Fkqm

Cite this article as: Hoffmann C, Liebers U, Humbsch P, et al. An adaptation strategy to urban heat: hospital rooms with radiant cooling accelerate patient recovery. ERJ Open Res 2021; 7: 00881-2020 [DOI: 10.1183/23120541.00881-2020].

\section{Abstract}

Background Patients with respiratory diseases are vulnerable to the effects of heat. Therefore, it is important to develop adaptation strategies for heat exposure. One option is to optimise the indoor environment. To this end, we equipped hospital patient rooms with radiant cooling. We performed a prospective randomised clinical trial to investigate potentially beneficial effects of the hospitalisation in rooms with radiant cooling on patients with a respiratory disease exacerbation.

Methods Recruitment took place in June, July and August 2014 to 2016 in the Charité Universitätsmedizin Berlin, Germany. We included patients with COPD, asthma, pulmonary hypertension, interstitial lung disease and pneumonia. 62 patients were allocated to either a standard patient room without air conditioning or a room with radiant cooling set to $23^{\circ} \mathrm{C}\left(73^{\circ} \mathrm{F}\right)$. We analysed the patients' length of stay with a Poisson regression. Physiological parameters, fluid intake and daily step counts were tested with mixed regression models.

Results Patients hospitalised in a room with radiant cooling were discharged earlier than patients in standard rooms $(\mathrm{p}=0.003)$. The study participants in chambers with radiant cooling had a lower body temperature $(\mathrm{p}=0.002)$, lower daily fluid intake $(\mathrm{p}<0.001)$, higher systolic blood pressure $(\mathrm{p}<0.001)$ and an increased daily step count $(\mathrm{p}<0.001)$.

Conclusion The results indicate that a radiant cooling system in hospital patient rooms provides clinical benefits for patients with respiratory disease exacerbations during the warm summer months, which may contribute to an earlier mobilisation. Radiant cooling is commended as a suitable adaptation strategy to reduce the clinical impact of climate warming.

\section{Introduction}

Heatwaves increase the number of emergency department visits by patients with pneumonia, influenza, bronchitis, emphysema and COPD [1]. High temperatures are associated with more respiratory symptoms [2] and hospitalisations, especially in the elderly population [3]. A previous study with COPD patients showed a reduction in exercise capacity, lung function and a worsened disease status during heat stress [4]. In view of global climate change, we have to prepare for even more intense and more frequent heatwaves in the future [5]. Therefore, it is important to develop adaptation strategies.

After studying the effects of heat on COPD patients, McCormack et al. [6] concluded that indoor environmental conditions should be optimised to protect this vulnerable high-risk group. An analysis by BRAGA et al. [7] demonstrated a positive effect of central air conditioning to reduce respiratory and 
cardiovascular deaths during hot days. Another study by Petкova et al. [8] on urban heat-related mortality in the USA attributed a rapid adaptation to heat since the 1970s to increased access to air conditioning.

As part of developing and evaluating an adaptation strategy to increasing urban heat, we equipped two hospital patient rooms with a radiant cooling system. Radiant cooling has the benefit of not requiring cool air circulation that might spread infection between patients. We initiated a prospective randomised clinical trial to investigate the benefits of regulating hospital room temperature with radiant cooling on a primary outcome measure of length of hospital stay, and secondary outcomes including cardiovascular and respiratory parameters, clinical improvement and physical activity. We chose the length of stay in hospital as the primary outcome as it is important to patients and is an important cost in the treatment of COPD exacerbations [9].

Methods

\section{Study design}

The prospective randomised controlled clinical trial was registered in the WHO-compliant registry Deutsches Register Klinischer Studien (German Clinical Trials Register, DRKS00004931) on 26 April 2013. The study was approved by the ethics committee of the Charité - Universitätsmedizin Berlin (EA1/ 279/11). We performed the study according to the principles of the Declaration of Helsinki. Written informed consent was obtained from every participating patient.

Recruitment took place from 1 June 2014 to 31 August 2016 in the Charité - Universitätsmedizin Berlin, Germany. To exclude patients with a possible exposure to cold temperatures from the study, recruitment was paused from the beginning of September to the end of May in each year.

The study population consisted of patients with respiratory diseases, hospitalised due to an acute episode of worsening respiratory symptoms that warranted treatment (which we termed an exacerbation). We included patients with COPD, asthma, pulmonary hypertension (PAH), interstitial lung disease (ILD) and pneumonia who presented acutely at an emergency room or were directly referred to the hospital by a local physician. Trained physicians made the diagnosis according to current guidelines. COPD diagnosis and

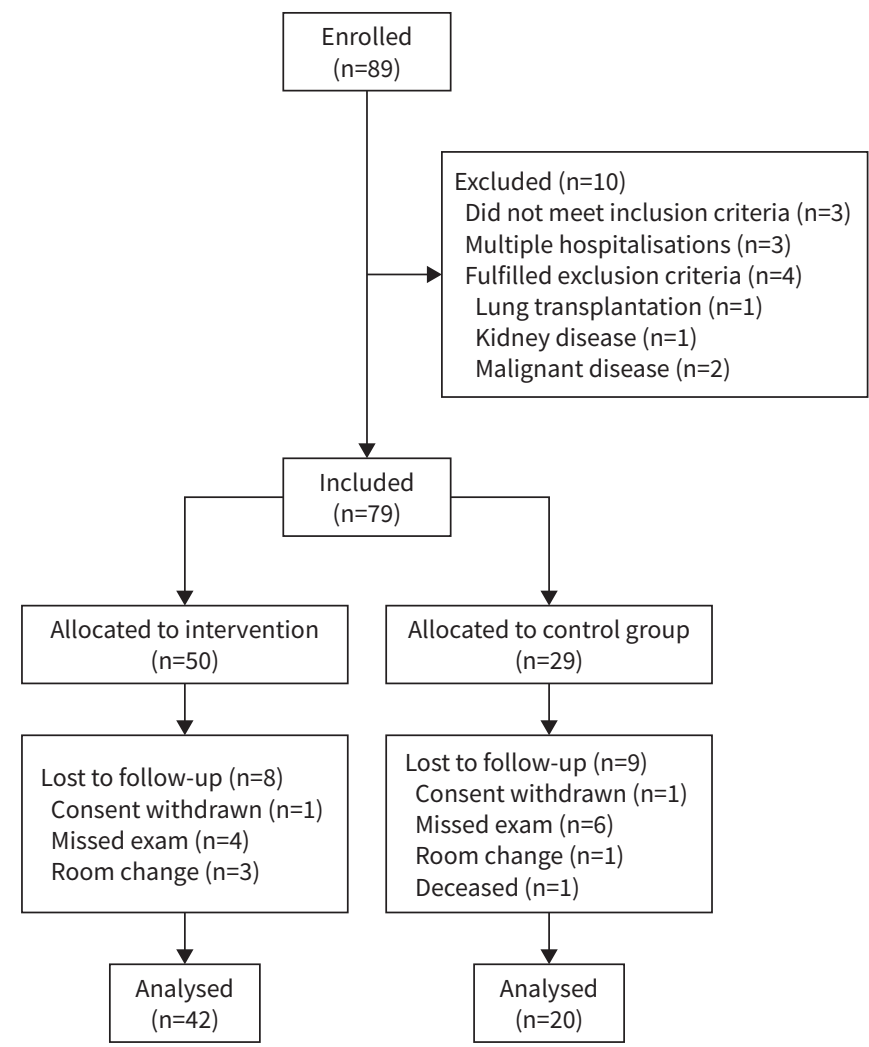

FIGURE 1 Study flow chart. 
staging were based on post-bronchodilator spirometry results, according to the Global Initiative for Chronic Obstructive Lung Disease (GOLD) classification [10]. For the diagnosis of asthma, the "Nationale Versorgungsleitlinien, 2. Auflage" were applied [11]. For PAH diagnosis, we used the guidelines from 2009 [12], which were updated during the study in 2015 [13]. ILD was diagnosed according to the "S2 K Leitlinie für Diagnose und Therapie der idiopathischen Lungenfibrose” [14]. The diagnosis of pneumonia was made using "Empfehlungen zur Therapie akuter Atemwegsinfektionen und der ambulant erworbenen Pneumonie” [15].

Exclusion criteria were lung cancer with a life expectancy of less than 6 months, a requirement for intensive care, unstable coronary disease, severe liver disease (Child-Pugh class C), severe kidney disease (glomerular filtration rate $\leqslant 29 \mathrm{~mL} \cdot \min \cdot 1.73 \mathrm{~m}^{-2}$ ), patient awaiting lung transplantation, inability to fulfil the testing and examination procedures, or the expectation of a room change before discharge. To avoid a bias in the results due to including the same patient multiple times, patients with repeated hospital admissions during the recruitment phase were included once only. Figure 1 shows the CONSORT diagram for the study; in total, we analysed the data of 62 patients.

\section{Study setting and randomisation}

We equipped two hospital patient rooms with capillary tube mats for air convection free temperature control (Clina Cooling Inc. by service provider S \& L Kühldecken und Heizungssysteme GmbH und Co. $\mathrm{KG}$, Mittenwalde, Germany). In a pilot phase prior to the study, most patients perceived $23^{\circ} \mathrm{C}$ to be a comfortable temperature $\left(21^{\circ} \mathrm{C}\right.$ and $22^{\circ} \mathrm{C}$ caused discomfort in several patients, who complained that the room was cold for them). Therefore, the radiant cooling system was set to maintain a room temperature of $23^{\circ} \mathrm{C}\left(73^{\circ} \mathrm{F}\right)$. The system served for temperature control only and did not modulate humidity. Both chambers with radiant cooling were shared rooms on the 4th floor, one for two, the other for three patients. For the control group, we used standard patient rooms of equal architecture in the same building on the 3rd and 4th floors, with equal conditions concerning daylight, position relative to the sun and nursing staff.

The randomisation was planned by the Coordinating Centre for Clinical Studies of the Charité Universitätsmedizin Berlin to ensure allocation concealment towards the study personnel until the moment of assignment. To prevent selection bias, patients were allocated to the two room types according to a randomisation list. Occasionally, new patients were allocated to the room with the only vacant bed to ensure separation by sex. This was a "real-world" study performed under conditions typical of a busy clinical department of pneumology.

\section{Sample size calculations}

Prior to this study, there were no data available on the effect size of radiant cooling on length of stay of hospitalised patients on which to base a power calculation. Our sample size was determined by as many patients as possible within the timescale and financial budget of the project.

\section{Data collection and endpoints}

Length of stay

The primary endpoint of the study was the patients' length of stay in the hospital. Patients were discharged by the physician who considered a number of factors including whether the patient was free of fever $\left(\leqslant 37.2^{\circ} \mathrm{C}\right)$, had a reduction in dyspnoea, cough and sputum, had a forced expiratory volume in $1 \mathrm{~s}\left(\mathrm{FEV}_{1}\right)$ $>15 \%$ predicted, and was haemodynamically stable (blood pressure $>90 \mathrm{mmHg}$, heart rate $<100 \mathrm{bpm}$ ).

\section{Questionnaires}

The COPD Assessment Test (CAT ${ }^{\mathrm{TM}}$, GlaxoSmithKline, (C2009) was used to evaluate the disease status of the COPD patients [16]. We also applied the Modified British Medical Research Council Questionnaire for Dyspnoea (mMRC) to assess symptom severity [17-19]. The patients answered both questionnaires at hospital admission and prior to discharge.

\section{Physiological measurements}

In physiological studies of heat stress, core body temperature, heart rate and average skin temperature are used as indicators of heat strain [20]. Heat causes vasodilation that will require increases in cardiac output and heart rate to maintain blood pressure and perfusion. Passive exposure to mild heat $\left(28.8^{\circ} \mathrm{C}\right.$ to $\left.37.5^{\circ} \mathrm{C}\right)$ has been studied by PALLUBinsky et al. [21], who showed that after acclimation, core body temperature and sweating decreased, and blood pressure was lowered. We included similar endpoints in our study, although instead of sweating, we monitored the patients' fluid intake. 
We measured the patients' weight with a scale (Kern \& Sohn GmbH, Balingen-Frommern, Germany) at admission and on the last day of hospitalisation. The body temperature was determined every morning in the patient's ear with a remote medical thermometer (B. Braun Melsungen AG, Melsungen, Germany). At the same time, blood oxygen saturation and heart rate were measured by pulse oximetry (Medtronic, Minneapolis, MN, USA). Blood pressure was determined with an automatic sphygmomanometer (ROESER Medical GmbH, Essen, Germany). Daily fluid intake was monitored by the nursing staff according to a mandatory standardised protocol.

\section{Activity tracking}

Upon hospital admission, patients were equipped with an activity tracking device, the Withings Pulse $\mathrm{O}_{2}{ }^{\mathrm{TM}}$ (Nokia Solutions and Networks GmbH \& Co. KG, Munich, Germany) to record daily step counts. The study participants were instructed to wear the activity tracker on their nondominant wrist and to only take it off for showering or bathing.

\section{Meteorological data}

The daily maximum and minimum outdoor temperatures illustrated in supplementary figure S2 were obtained from the website of the German Meteorological Office (Deutscher Wetterdienst, www.dwd.de). The temperatures were measured by a meteorological station located in the urban area of Berlin at $48 \mathrm{~m}$ above sea level on $52.47^{\circ} \mathrm{N}$ and $13.40^{\circ} \mathrm{E}$, the former Berlin-Tempelhof airport area.

\section{Statistical analysis}

The statistical analysis was performed with SPSS Statistics for Windows, Version 25 (IBM Corp., Armonk, NY, USA). Supplementary figure S2 was plotted using GraphPad Prism, Version 4 (GraphPad Software, San Diego, CA, USA). Data were descriptively analysed and reported as median, minimum and maximum values. To compare the control and intervention groups, we applied Mann-Whitney U-tests and chi-squared tests. Wilcoxon signed-rank tests were used to compare the data collected at admission and at discharge on the same patient. Length of stay was analysed as the dependent variable of a Poisson regression with room type as independent variable. The relationships between length of stay and sex, age, body mass index (BMI), smoking status and medication were also examined. Mixed-effects linear

TABLE 1 Characteristics of the different patient cohorts hospitalised in rooms with or without radiant cooling

\begin{tabular}{|c|c|c|c|}
\hline Parameter & Room without radiant cooling & Room with radiant cooling & $\mathrm{p}$-value \\
\hline Patients included, $\mathrm{n}$ & 20 & 42 & - \\
\hline Female, $\mathrm{n}()$ & $9(45.0)$ & $11(26.2)$ & 0.139 \\
\hline Age, years, median (range) & $65(48-84)$ & $66(32-85)$ & 0.757 \\
\hline $\mathrm{BMI}, \mathrm{kg} \cdot \mathrm{m}^{-2}$, median (range) & $23(17-53)$ & $27(16-42)$ & $0.024^{\star}$ \\
\hline Smoker, \% & - & $10.3^{\#}$ & 0.320 \\
\hline Former smoker, \% & $83.3^{4}$ & $79.5^{\#}$ & 0.320 \\
\hline Non-smoker, \% & $16.7^{\bullet}$ & $10.3^{\#}$ & 0.320 \\
\hline \multicolumn{4}{|l|}{ Diagnosed condition, $\mathrm{n}(\%)$} \\
\hline COPD & $19(95.0)$ & $37(88.1)$ & 0.390 \\
\hline GOLD 1 & - & $5.9^{+}$ & 0.496 \\
\hline GOLD 2 & $14.3^{\S}$ & $20.6^{+}$ & 0.496 \\
\hline GOLD 3 & $35.7^{\S}$ & $44.1^{+}$ & 0.496 \\
\hline GOLD 4 & $50.0^{\S}$ & $29.4^{+}$ & 0.496 \\
\hline GOLD A & - & - & 0.563 \\
\hline GOLD B & $50.0^{\S}$ & $40.0^{+}$ & 0.563 \\
\hline GOLD C & - & - & 0.563 \\
\hline GOLD D & $50.0^{\S}$ & $60.0^{+}$ & 0.563 \\
\hline Asthma & $3(15.0)$ & $7(16.7)$ & 0.868 \\
\hline Pulmonary hypertension & $4(20.0)$ & $3(7.1)$ & 0.135 \\
\hline Interstitial lung disease & $2(10.0)$ & $2(4.8)$ & 0.433 \\
\hline Pneumonia & $7(35.0)$ & $6(14.3)$ & 0.061 \\
\hline Neoplasia & $1(5.0)$ & $1(2.4)$ & 0.585 \\
\hline
\end{tabular}

Comparisons were made by chi-squared test or Mann-Whitney U-test. ${ }^{*} p<0.05$. BMI: body mass index; GOLD: Global Initiative for Chronic Obstructive Lung Disease. "Three patients did not disclose their smoking status, valid percent, adds up to more than $100 \%$ due to rounding error. "Two patients did not disclose their smoking status, valid percent is reported. ${ }^{+}$Missing data for 8 patients, valid percent. ${ }^{\S}$ Missing data for 6 patients, valid percent. 
regression models were used to investigate the effect of room type on the repeated measures of body temperature, blood pressure, heart rate, oxygen saturation, daily fluid intake and daily step count, with adjustment for sex, age, BMI and smoking status as covariates. p-values less than 0.05 were considered statistically significant.

Results

Study population

The characteristics of the two study groups are reported in table 1.

The study participants were mainly COPD patients, often with a coexistent respiratory condition. Of the six included patients without COPD, two patients each were admitted to the hospital with an acute episode of worsening respiratory symptoms of pneumonia, asthma or ILD. Patients allocated to the different room types were of similar age, sex, smoking status and diagnosed respiratory conditions. Patients in the rooms with radiant cooling had a significantly higher BMI ( $p=0.024$, Mann-Whitney U-test).

During June, July and August, the daily temperatures in the standard patient rooms varied between $21.5^{\circ} \mathrm{C}$ and $28.2^{\circ} \mathrm{C}$, with an average value of $24.0^{\circ} \mathrm{C}$, while the radiant cooling system maintained a stable room temperature of $23.0^{\circ} \mathrm{C}$. A box-and-whisker plot of the temperatures in the two room types is provided as supplementary figure S1. The outdoor temperatures are illustrated in supplementary figure S2.

\section{Comparison of control and intervention groups}

Figure 2 and table 2 show the results for the primary outcome measure, length of hospital stay, which was significantly shorter for patients hospitalised in a room with radiant cooling compared to patients residing in a standard room $(\mathrm{p}=0.003$, Poisson regression). A multivariate Poisson regression model with both

a) Conventional room

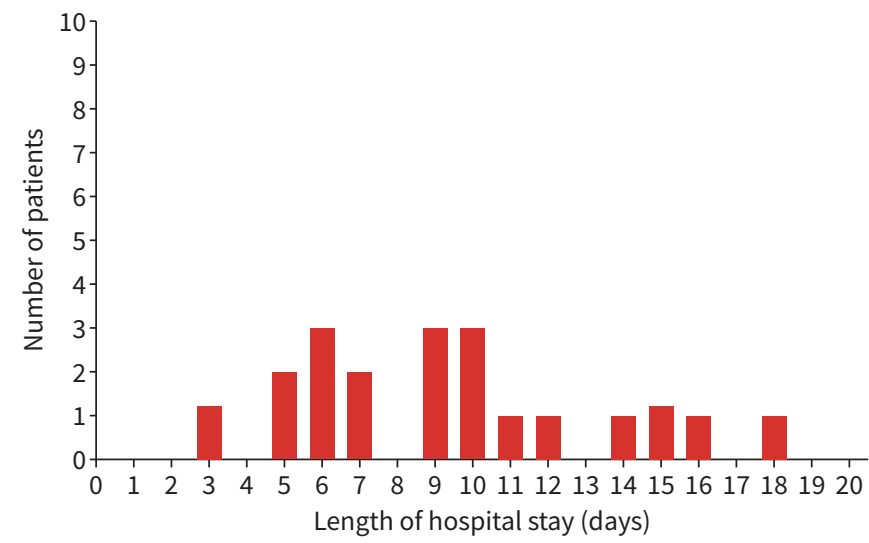

b) Radiant cooled room

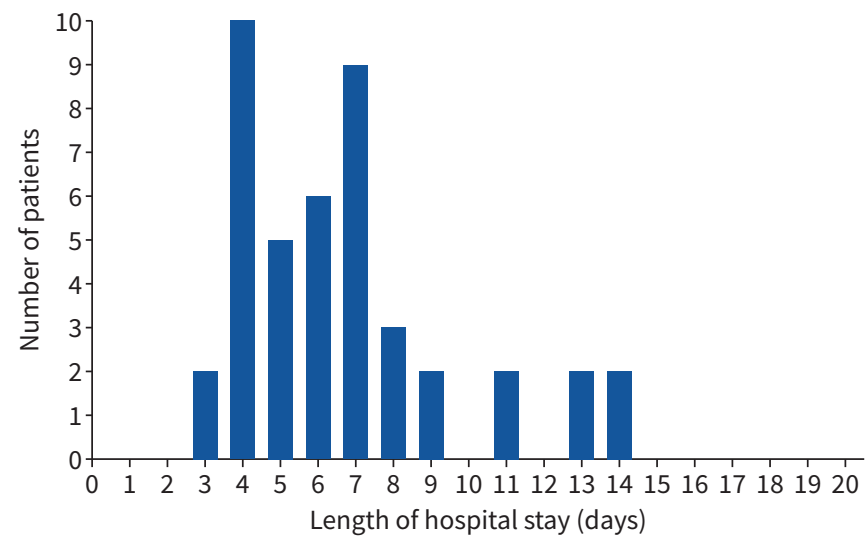

FIGURE 2 Length of hospital stay in each group. The upper panel a) illustrates the length of hospital stay in the conventional patient rooms. The lower panel b) shows the hospitalisation duration in the rooms with radiant cooling. 


\begin{tabular}{|c|c|c|c|}
\hline Parameter & Room without radiant cooling & Room with radiant cooling & p-value \\
\hline Length of hospital stay, median (range) & 9 days $(3-18)$ & 6 days $(3-14)$ & 0.003 \\
\hline \multicolumn{4}{|l|}{ CAT, median (range) } \\
\hline Admission & $27(15-36)$ & $28(11-38)$ & 0.556 \\
\hline Discharge & $23(1-32)$ & $23(6-36)$ & 0.864 \\
\hline \multicolumn{4}{|l|}{ mMRC, median (range) } \\
\hline Admission & $3(1-4)$ & $4(0-4)$ & 0.176 \\
\hline Discharge & $3(0-4)$ & $3(0-4)$ & 0.812 \\
\hline \multicolumn{4}{|l|}{ Body weight, median (range) } \\
\hline Admission & $61 \mathrm{~kg}(44-152)$ & $80 \mathrm{~kg}(48-138)$ & $0.002^{\star \star}$ \\
\hline Discharge & $61 \mathrm{~kg}(44-100)$ & 76 kg (46-110) & $0.049^{\star}$ \\
\hline
\end{tabular}

control and intervention groups combined showed that length of stay was independent of sex $(\mathrm{p}=0.290)$, smoking status $(\mathrm{p}=0.157)$ and BMI $(\mathrm{p}=0.235)$. The patient's age influenced the hospitalisation duration $(p=0.047)$; each year of age increased stay by $1.1 \%$ (95\% CI $1.000-1.022)$.

Table 2 shows the results for questionnaires on health status (CAT) and dyspnoea severity (mMRC) in the two room types.

Table 3 summarises the patients' disease status and weight at admission and at discharge from the hospital. The CAT score of the COPD patients improved during the hospital stay, regardless of the patient room type (w/o cooling $\mathrm{p}=0.016$; with cooling $\mathrm{p}=0.001$, Wilcoxon signed-rank test). We recorded no significant weight changes during the patients' stay at the hospital.

The results of the mixed regression modelling are displayed in table 4. The study participants in the rooms with radiant cooling had a higher systolic blood pressure $(p<0.001)$, lower body temperature $(p=0.002)$, lower daily fluid intake $(\mathrm{p}<0.001)$ and an increased daily step count $(\mathrm{p}<0.001)$. Supplementary table S1 provides information on minimum, maximum and median values of the recorded physiologic parameters.

Figure 3 shows the activity tracking results, illustrating the higher daily step counts for patients in the radiant cooled room compared to the daily step count of patients hospitalised in conventional rooms. Daily step count data were provided by 8 patients from the control group and 14 intervention group patients. Data were only provided by patients who agreed to be monitored at hospital admission and who were ambulatory.

A comparison of the patient's medication at hospital discharge by room type using chi-squared tests revealed differences in the frequencies of treatment, with less treatment with systemic corticosteroids

TABLE 3 Comparison of the clinical status and body weight dynamics between admission and discharge of the patients

\begin{tabular}{|c|c|c|c|}
\hline Parameter & Admission & Discharge & $\mathrm{p}$-value \\
\hline \multicolumn{4}{|l|}{ CAT, median (range) } \\
\hline Room without cooling & $27(15-36)$ & $23(1-32)$ & $0.016^{\star}$ \\
\hline Room with cooling & $28(11-38)$ & $23(6-36)$ & $0.001^{\star *}$ \\
\hline \multicolumn{4}{|l|}{ mMRC, median (range) } \\
\hline Room without cooling & $3(1-4)$ & $3(0-4)$ & 1.000 \\
\hline Room with cooling & $4(0-4)$ & $3(0-4)$ & 0.149 \\
\hline \multicolumn{4}{|c|}{ Body weight, median (range) } \\
\hline Room without cooling & $61 \mathrm{~kg}(44-152)$ & $61 \mathrm{~kg}(44-100)$ & 0.715 \\
\hline Room with cooling & $80 \mathrm{~kg}(48-138)$ & 76 kg (46-110) & 0.102 \\
\hline
\end{tabular}




\begin{tabular}{|c|c|c|c|c|c|}
\hline \multirow[t]{2}{*}{ Dependent variables } & \multicolumn{5}{|c|}{$\mathrm{p}$-values of independent variables } \\
\hline & Age & Sex & BMI & Smoking status & Room type \\
\hline Body temperature ${ }^{\#}$ & 0.270 & 0.064 & 0.083 & 0.155 & $0.002^{\star \star}$ \\
\hline \multicolumn{6}{|l|}{ Blood pressure" } \\
\hline Systolic & $<0.001^{\star \star \star}$ & $<0.001^{\star \star \star}$ & $0.044^{\star}$ & $0.001^{\star \star}$ & $<0.001^{\star \star \star}$ \\
\hline Diastolic & $<0.001^{\star \star \star}$ & $<0.001^{\star \star \star}$ & 0.623 & 0.089 & 0.162 \\
\hline Heart rate & $<0.001^{\star \star \star}$ & 0.415 & 0.081 & 0.768 & 0.760 \\
\hline Oxygen saturation & 0.071 & 0.471 & 0.645 & 0.258 & 0.163 \\
\hline Daily fluid intake & 0.090 & $<0.001^{\star \star \star}$ & $0.010^{\star}$ & 0.141 & $<0.001^{\star \star \star}$ \\
\hline Daily step count & $<0.001^{\star \star \star}$ & $<0.001^{\star \star \star}$ & 0.083 & 0.797 & $<0.001^{\star \star \star}$ \\
\hline
\end{tabular}

BMI: body mass index; Smoking status: smoker/former smoker/non-smoker. "Measured in the morning with an ear thermometer. "Measured in the morning. ${ }^{\star} p<0.05 ;{ }^{\star \star} p<0.01 ;{ }^{\star \star \star} p<0.001$.

$(p=0.046)$ and angiotensin-converting enzyme (ACE) inhibitors $(p=0.001)$ in the room with radiant cooling (shown in table 5). Time to discharge was not related to treatment with systemic corticosteroids $(\mathrm{p}=0.395)$ or ACE inhibitors $(\mathrm{p}=0.830)$ in a multivariate Poisson regression model.

\section{Discussion}

\section{Length of stay}

The main finding of our study is that patients with a respiratory disease exacerbation during the warm summer season could be discharged significantly earlier from hospital if their patient room was equipped with a radiant cooling system. This agrees with SHAJAHAN et al. [22], who recently reviewed the scientific evidence for the effects of indoor environmental parameters on medical outcomes. They reported that heating, ventilation and air conditioning (HVAC) systems would enhance the patients' healing process and reduce the length of hospital stay if appropriately designed, although most of the research was based on simulation. Our study translates the theoretical and climatic chamber studies into the hospital setting and therefore provides much needed real-world evidence. Lomas and GiRIDHARAn [23] investigated the resilience of buildings in the UK to climate change. Their analysis of the thermal comfort in a hospital includes the statement that radiant cooling is a useful way to enhance thermal resilience at relatively low energy demand.

\section{The COPD Assessment Test (CATTM)}

The summary of our results in table 2 shows that the patient cohorts in both room types had a comparable CAT score at admission $(\mathrm{p}=0.556)$. At discharge, the median CAT score had improved in both groups (room without cooling $\mathrm{p}=0.016$; with cooling $\mathrm{p}=0.001$ ). This emphasises that the control and intervention groups had a comparable health status at admission and discharge.

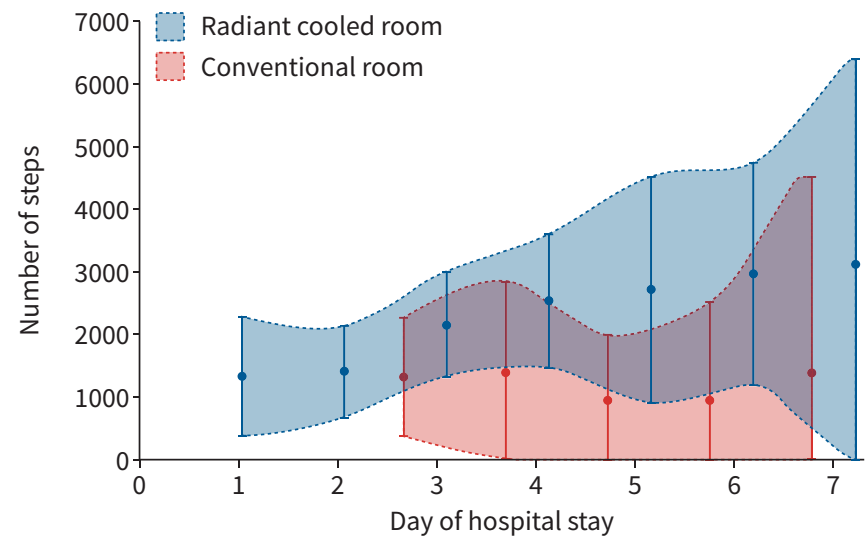

FIGURE 3 Activity tracking results. Displayed are mean values of step counts (dots) and 95\% confidence intervals (whiskers). The activity data originate from the following number of patients: day $1, n=9$; day $2, n=10$; day $3, n=18$; day $4, n=16$; day $5, n=13$; day $6, n=10$; day $7, n=9$. 
TABLE 5 Patients' medication by room type

\begin{tabular}{|c|c|c|c|}
\hline Treatment & Room without radiant cooling \% & Room with radiant cooling $\%$ & p-value \\
\hline LABA, n (\%) & $12(60)$ & $33(79)$ & 0.205 \\
\hline LAMA, $n(\%)$ & $13(65)$ & $28(67)$ & 0.892 \\
\hline SABA, $n(\%)$ & $8(40)$ & $26(62)$ & 0.149 \\
\hline SAMA, $n(\%)$ & $5(25)$ & $11(26)$ & 0.992 \\
\hline ICS, n (\%) & $9(45)$ & $27(64)$ & 0.213 \\
\hline Systemic corticosteroid, n (\%) & $12(60)$ & $15(36)$ & $0.046^{*}$ \\
\hline Methylxanthine, n (\%) & $1(5.0)$ & $11(26)$ & 0.057 \\
\hline Leukotriene antagonist, $\mathrm{n}(\%)$ & $0(0.0)$ & $2(4.8)$ & 0.333 \\
\hline Angiotensin-II-receptor antagonist, $\mathrm{n}(\%)$ & $1(5.0)$ & $7(17)$ & 0.222 \\
\hline ACE inhibitor, $n(\%)$ & $12(60)$ & $8(19)$ & $0.001^{\star *}$ \\
\hline Beta blocker & $7(35)$ & $13(31)$ & 0.650 \\
\hline Diuretic & $9(45)$ & $20(48)$ & 0.986 \\
\hline
\end{tabular}

Physiological measurements and daily step count tracking

In the radiant cooling arm of our study, we observed a reduced body temperature and fluid intake, indicative of less heat stress, and higher systolic blood pressure, suggestive of less vasodilation of surface blood vessels in the cooling environment. The higher daily step count of patients hospitalised in the radiant cooled rooms could be explained by an earlier mobilisation. The mechanism by which climate control will benefit patients is unknown but cooling during warm weather might reduce breathlessness. The impact of cold air on COPD patients has been previously investigated by SPENCE et al. [24]. An experiment with 19 COPD patients showed a reduced breathlessness score after cycle ergometry exercise when breathing cold air compared to room air and an improved peak exercise performance. SchwARTzSTEIN et al. [25] found that a flow of cold air directed against the face reduced breathlessness in 16 healthy study participants. The mMRC dyspnoea score did not capture an improvement of the clinical status between admission and discharge in our study, probably due to the symptom severity scale having only four steps.

\section{Limitations}

The temperature of the room could not be hidden from the patient or healthcare professionals treating the patient, and so this is an unblinded study. However, objective clinical parameters suggest a speedier recovery. The radiant cooling system did not regulate air humidity. We did not measure humidity in the rooms, or calculate any indices expressing perceived temperatures.

Despite randomisation, there was an imbalance between weight and BMI in room allocation, with a median BMI of 27 in the intervention group compared to a median BMI of 23 in the control group (see table 1). This imbalance occurred by chance, as the room allocation was not stratified for any patient characteristics. Subsequent studies should use a case-control matching or stratify for sex, age and BMI at randomisation. Nevertheless, our results showed no dependency between BMI and length of stay $(\mathrm{p}=0.235$, Poisson regression).

In a previous study, we were able to show that patients with pulmonary hypertension have a decreasing daily step count with rising maximum outdoor temperature $(r=-0.47, \mathrm{p}<0.001)$ [26]. Therefore, we chose step counts as an endpoint of our present study not only as a measure for early mobilisation, but also as an indicator of heat stress. Due to poor compliance of some patients, who did not wear the activity tracker $24 \mathrm{~h}$ a day, we were unable to compare daytime and night-time movements.

It is known that comorbidity increases vulnerability to the effects of heat [27]. Our study was too small to examine cardiovascular and metabolic comorbidities admitted with an exacerbation of their respiratory disease. We would recommend that future studies should also focus more on multi- or comorbidity.

\section{Conclusion}

The results indicate that radiant cooling systems in hospital patient rooms provide clinical benefits for patients with respiratory disease exacerbations during warm summer months and contribute to an earlier mobilisation. Equipping patient rooms with air convection free radiant cooling is commended as a suitable adaptation strategy to reduce the clinical impact of a warming climate. 
Acknowledgements: We thank all patients for their participation. We are grateful to Jana B. Heinsohn (Charité, Dept of Outpatient Pneumology) for her contribution to data collection. The assistance of Tatiana Nikitina, Jenny Kollek and Grit Müller (Charité, Dept of Outpatient Pneumology) with data entry is much appreciated.

This study is registered at www.drks.de with identifier number DRKS00004931. Deposition of the study data on a public data sharing platform is not planned.

Conflict of interest: C. Hoffmann has nothing to disclose. U. Liebers reports personal fees for consultations and lectures from AstraZeneca $\mathrm{GmbH}$, Berlin-Chemie AG, Boehringer Ingelheim $\mathrm{GmbH}$, Bristol-Myers Squibb, GlaxoSmithKline, Novartis Pharma GmbH and Roche Pharma AG. P. Humbsch has nothing to disclose. M. Drozdek has nothing to disclose. G. Bölke has nothing to disclose. P. Hoffmann has nothing to disclose. A. Holzgreve has nothing to disclose. G.C. Donaldson reports grants from AstraZeneca, and personal fees from AstraZeneca, the American Thoracic Society and FWO Flanders, outside the submitted work. C. Witt reports grants from Deutsche Forschungsgemeinschaft during the conduct of the study; and personal fees from MSD, AstraZeneca, Bristol-Myers Squibb, GlaxoSmithKline, Takeda and Berlin-Chemie, outside the submitted work.

Support statement: The project was funded by Deutsche Forschungsgemeinschaft grant FOR 1736 "Urban Climate and Heat Stress in mid-latitude Cities in View of Climate Change" (UCaHS), Project "Medical Vulnerability" WI 1516/ 2-1. The sponsor was not involved in any stages from study design to manuscript submission. Funding information for this article has been deposited with the Crossref Funder Registry.

\section{References}

1 Fuhrmann CM, Sugg MM, Konrad CE, et al. Impact of extreme heat events on emergency department visits in North Carolina (2007-2011). J Community Health 2016; 41: 146-156.

2 Näyhä S, Rintamäki H, Donaldson G, et al. Heat-related thermal sensation, comfort and symptoms in a northern population: the National FINRISK 2007 study. Eur J Public Health 2014; 24: 620-626.

3 Michelozzi P, Accetta G, De Sario M, et al. High temperature and hospitalizations for cardiovascular and respiratory causes in 12 European cities. Am J Respir Crit Care Med. 2009; 179: 383-389.

4 Jehn M, Donaldson G, Kiran B, et al. Tele-monitoring reduces exacerbation of COPD in the context of climate change - a randomized controlled trial. Environ Health Glob Access Sci Source 2013; 12: 99.

5 Meehl GA, Tebaldi C. More intense, more frequent, and longer lasting heat waves in the 21st century. Science 2004; 305: 994-997.

6 McCormack MC, Belli AJ, Waugh D, et al. Respiratory effects of indoor heat and the interaction with air pollution in chronic obstructive pulmonary disease. Ann Am Thorac Soc. 2016; 13: 2125-2131.

7 Braga ALF, Zanobetti A, Schwartz J. The effect of weather on respiratory and cardiovascular deaths in 12 U.S. cities. Environ Health Perspect. 2002; 110: 859-863.

8 Petkova EP, Vink JK, Horton RM, et al. Towards more comprehensive projections of urban heat-related mortality: estimates for New York City under multiple population, adaptation, and climate scenarios. Environ Health Perspect. 2017; 125: 47-55.

9 Toy EL, Gallagher KF, Stanley EL, et al. The economic impact of exacerbations of chronic obstructive pulmonary disease and exacerbation definition: a review. COPD 2010; 7: 214-228.

10 Vogelmeier CF, Criner GJ, Martinez FJ, et al. Global Strategy for the Diagnosis, Management and Prevention of Chronic Obstructure Lung Disease 2017 Report: GOLD Executive Summary. Respirology 2017; 22: 575-601.

11 Abholz HH, Berdel D, Buhl R, et al. Nationale VersorgungsLeitlinie Asthma, 2. Auflage (updated 11/2010). Dtsch Arztebl 2011; 108: A-596.

12 Galiè N, Hoeper MM, Humbert M, et al. Guidelines for the diagnosis and treatment of pulmonary hypertension. Eur Respir J. 2009; 34: 1219-1263.

13 Galiè N, Humbert M, Vachiery J-L, et al. 2015 ESC/ERS Guidelines for the diagnosis and treatment of pulmonary hypertension: The Joint Task Force for the Diagnosis and Treatment of Pulmonary Hypertension of the European Society of Cardiology (ESC) and the European Respiratory Society (ERS): Endorsed by: Association for European Paediatric and Congenital Cardiology (AEPC), International Society for Heart and Lung Transplantation (ISHLT). Eur Respir J. 2015; 46: 903-975.

14 Behr J, Günther A, Ammenwerth W, et al. S2K-Leitlinie zur Diagnostik und Therapie der idiopathischen Lungenfibrose. Pneumologie 2013; 67: 81-111.

15 Arzneimittelkommission der deutschen Ärzteschaft, editor. Empfehlungen zur Therapie akuter Atemwegsinfektionen und der ambulant erworbenen Pneumonie. 3rd ed. Berlin: Arzneimittelkommission der deutschen Ärzteschaft; 2013.

16 Jones PW, Harding G, Berry P, et al. Development and first validation of the COPD assessment test. Eur Respir J. 2009; 34: 648-654.

17 Fletcher CM, Elmes PC, Fairbairn AS, et al. Significance of respiratory symptoms and the diagnosis of chronic bronchitis in a working population. Br Med J 1959; 2: 257-266. 
Standardized questionaries on respiratory symptoms. Br Med J 1960; 2: 1665

McGavin CR, Artvinli M, Naoe H, et al. Dyspnoea, disability, and distance walked: comparison of estimates of exercise performance in respiratory disease. $\mathrm{Br}$ Med J. 1978; 2: 241-243.

Garzón-Villalba XP, Wu Y, Ashley CD, et al. Ability to discriminate between sustainable and unsustainable heat stress exposures. Part 2: physiological indicators. Ann Work Expo Health 2017; 61: 621-632.

Pallubinsky $\mathrm{H}$, Schellen L, Kingma BRM, et al. Thermophysiological adaptations to passive mild heat acclimation. Temp Austin Tex 2017; 4: 176-186.

Shajahan A, Culp $\mathrm{CH}$, Williamson B. Effects of indoor environmental parameters related to building heating, ventilation, and air conditioning systems on patients' medical outcomes: a review of scientific research on hospital buildings. Indoor Air 2019; 29: 161-176.

3 Lomas KJ, Giridharan R. Thermal comfort standards, measured internal temperatures and thermal resilience to climate change of free-running buildings: a case-study of hospital wards. Build Environ. 2012; 55: 57-72.

4 Spence DP, Graham DR, Ahmed J, et al. Does cold air affect exercise capacity and dyspnea in stable chronic obstructive pulmonary disease? Chest 1993; 103: 693-696.

5 Schwartzstein RM, Lahive K, Pope A, et al. Cold facial stimulation reduces breathlessness induced in normal subjects. Am Rev Respir Dis. 1987; 136: 58-61.

Jehn M, Gebhardt A, Liebers U, et al. Heat stress is associated with reduced health status in pulmonary arterial hypertension: a prospective study cohort. Lung 2014; 192: 619-624.

7 Lavigne E, Gasparrini A, Wang X, et al. Extreme ambient temperatures and cardiorespiratory emergency room visits: assessing risk by comorbid health conditions in a time series study. Environ Health Glob Access Sci Source 2014; 13: 5. 